\title{
ISOLAMENTO, CARACTERIZAÇÃO E TESTES ANTAGÔNICOS DE BACTÉRIAS LÁTICAS DE ÁGUA DE CRIATÓRIOS DE PEIXES.
}

\author{
Nathalee Santos dos Santos ${ }^{1}$ e Elinalva Maciel Paulo ${ }^{2}$ \\ 1. Estágio PEVIC/CNPq, Graduando em Engenharia de Alimentos, Universidade \\ Estadual de Feira de Santana, email: nathaleesantos@ hotmail.com \\ 2. Orientador, Departamento de Ciências Biológicas, Universidade Estadual de Feira de \\ Santana, \\ e-mail: elinalvamaciel@yahoo.com.br
}

PALAVRAS-CHAVE: Bactérias lácticas, probióticos, piscicultura.

\section{INTRODUÇÃO}

A aquicultura mundial destaca-se como um dos setores da produção animal em elevada expansão. Nesta última década, obteve-se um crescimento anual médio cinco vezes superior as atividades agrícolas, superior à avicultura, suinocultura e produção de bovinos (Borguetti; Ostrensky, Borghetti, 2003; IBAMA, 2007). Esta atividade que vem crescendo em um ritmo de aproximadamente $30 \%$ ao ano no Brasil, e isso ocorre porque a lucratividade que pode apresentar é muito boa, proporcionando um rápido retorno do capital investido pelo produtor rural (Ostrensky, 1998). Segundo Costa (2003), com o crescimento da piscicultura intensiva, observa-se o aumento da ocorrência de enfermidades, pois os peixes ficam mais expostos a patógenos oportunistas. Diversos fatores tais como o regime alimentar, qualidade da água, ou até mesmo o manejo, que pode determinar mudanças na composição da microbiota intestinal que induzem a proliferação desses patógenos, provocando uma enfermidade (Verschuere, et al, 2000; Winton, 2001).

Um método alternativo, que está sendo aceito na indústria da aquicultura, é a utilização de bactéria probiótica para controlar eventuais patógenos (Gomez-Gil et al., 2000; Olafsen, 2001). Além disto, os probióticos podem trazer outros efeitos fisiológicos favoráveis ao hospedeiro, como imunoestimulação e disponibilidade de enzimas digestórias (Fuller, 1989). Estes microrganismos vivos ao serem ministrados a tanques de cultivo atuam beneficamente no organismo aquático de interesse, seja melhorando o consumo ou absorção da ração, o sistema imunológico, balanço de bactérias no trato intestinal, ou o ambiente de cultivo (viveiro) (Verschuere, et al, 2000).

Vários microrganismos são usados como probióticos, entre eles as bactérias ácido láticas, bactérias não ácido-láticas e leveduras (Coppola; Turnes, 2004).

Portanto o proposito deste trabalho consiste no isolamento de bactérias láticas benéficas da água de viveiros de peixes, visando posteriormente a sua prospecção como agentes probióticos que poderão atuar para uma possível redução de microrganismos patogênicos nos peixes e para o desenvolvimento de produtos tecnológicos para este fim podendo assim contribuir para a melhoria da piscicultura e crescimento da atividade.

\section{MATERIAL E MÉTODOS}

Foram coletadas duas amostras de água de viveiros de peixes em duas diferentes propriedades piscicultoras nas regiões do distrito de São Bráz, município de Santo Amaro da Purificação, Bahia, e em Conceição do Coité, Bahia (Figura 1). Estas foram identificadas como A e B respectivamente. A pesquisa foi executada no Laboratório de 
Microbiologia Aplicada e Saúde Pública (LAMASP/UEFS) do Departamento de Ciências Biológicas da Universidade Estadual de Feira de Santana (UEFS).
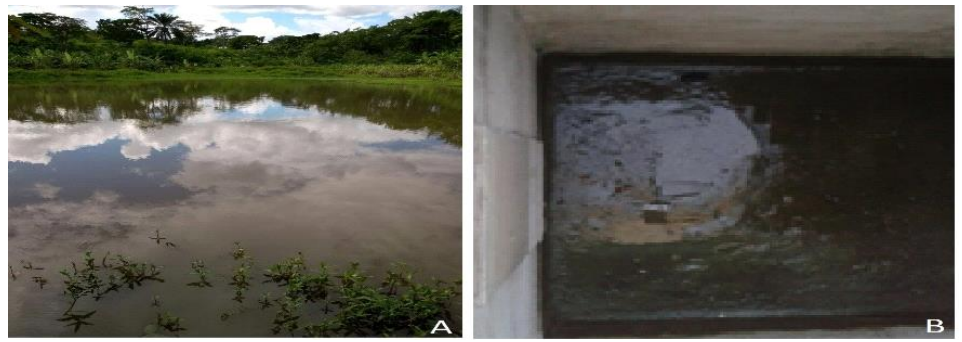

Figura1. Psiculturas de coletas das amostras: A (Santo Amaro da Purificação, BA) e B (Conceição do Coité, BA).

Para o isolamento de bactérias láticas, foram recolhidas cerca de $100 \mathrm{~mL}$ da água dos viveiros de peixes. As amostras (A e B) foram diluídas $\left(10^{-1}\right.$ a $10^{-7)}$ em solução tampão fosfato $\mathrm{pH}$ 7.2. A partir daí, foi realizada em triplicata a semeadas por esgotamento por estrias no ágar MRS (DE MAN, ROGOSA e SHARPE) e incubadas na estufa a $35^{\circ} \mathrm{C} / 48 \mathrm{~h}$ em jarra de anaerobiose. De cada placa contendo as respectivas diluições foram retiradas três colônias isoladas e novamente semeadas por esgotamento em estrias, em placas contendo MRS. Duas destas colônias foram transferidas para tubos contendo o meio de cultura MRS e incubadas após $48 \mathrm{~h}$ onde foram transferidas para tubos contendo ágar MRS inclinado na estufa a $35^{\circ} \mathrm{C} / 48 \mathrm{~h}$. Essas bactérias foram ativadas e checadas quanto à purificação de acordo com Axelsson (1993), realizando também a técnica de coloração de Gram e o teste de catalase. Após os testes realizados na amostra A, e não obtendo resultados para o crescimento de bactérias ácido-láticas, o experimento foi finalizado, realizando assim os experimentos para a amostra B.

A inibição do crescimento de bactérias lática frente a microrganismos patógenos para a amostra B, foi efetuada por meio do método difusão em disco, técnica descrita por Kirby e Bauer em 1966; e pelo método de cultura mista (Silva, 2015).

\section{RESULTADOS E DISCUSSÃO}

No isolamento e seleção de microrganismos em água de viveiros das amostras, não foi observada a presença de bactérias ácido-lácticas na amostra $\mathrm{A}$, entretanto, esta apresentou colônias de leveduras, e na amostra B foi observado a presença de bactérias ácido lácticas, Bacillus subtillis e leveduras em maior predominância meio de cultura MRS nas placas esgotamento por estrias e nos tubos contendo ágar MRS inclinado, incubadas a $35^{\circ} \mathrm{C}$ por $48 \mathrm{~h}$ em jarra de anaerobiose. Estas apresentaram em suas formas típicas, ou seja, ovaladas e alongadas com formação de esporos arredondados. Visto assim, outros testes foram realizados a fim obter outros resultados.

No presente trabalho, foram identificados pela técnica de Gram, microrganismos Gram positivos para as duas amostras analisadas (A e B), que se coraram em roxoazulado. O morfotipo para a amostra A encontrado foi para leveduras, e na amostra B apesar da predominância de leveduras apresentaram também em menor quantidade bactérias ácido lácticas e Bacillus sp.. O teste de catalase foi considerado positivo para as duas amostras, havendo a formação imediata de bolhas.

$\mathrm{Na}$ amostra $\mathrm{B}$, a presença de bactérias ácido lácticas, foi sugerida pelas caraterísticas morfológicas apresentadas na coloração de Gram, e pelo valor do $\mathrm{pH}$, ácido da cultura (4,2). Porém, como existia predominâncias de bactérias do gênero Bacillus sp 
e leveduras, não foi possivel isolar as bactérias láticas, apresentando sempre o resultado de catalase positiva, quando tentava obter colônias isoladas.

Usualmente, testes in vitro de antagonismo frente à patógenos, baseados na produção de compostos inibitórios ou na competição por nutrientes, são utilizados para selecionar potenciais bactérias probióticas (Gildberg et al., 1995; Huys et al., 2001; Vine et al., 2004; Vázquez et al., 2005). Neste trabalho, as cepas isoladas da água de viveiros de peixes paras as amostras A e B não apresentaram inibição do crescimento in vitro frente aos microrganismos patógenos Salmonella spp., Escherichia coli $e$ Straphylococcus, para o métodos de difusão em disco (Kirby \& Bauer (1966); Paulo (1991)), e método de cultura mista (SILVA, 2015), observando crescimento bacteriano quando confrontada com os enteropátogenos.

As bactérias lácticas são caracterizadas por serem gram-positivas, anaeróbicas ou anaeróbicas aerotolerantes, imóveis, não esporuladas, catalase negativa, carência de citocromos e produzem ácido lático como maior produto final do se metabolismo (Ringo \& Gatesoupe, 1998). Diferentes gêneros de bacterias lácticas (Streptococcus, Lactococcus, Vagococcus, Enterococcus, Lactobacillus, Carnobacterium, Aerococcus) se adaptaram a crescer em diferentes condições ambientais (Farzanfar, 2006). Contudo, elas não são dominantes na microbiota aquática e, consequentemente no trato intestinal de organismos aquáticos. Muitas tentativas têm sido realizadas no intuito de induzir uma dominância artificial destas bactérias (Gatesoupe, 1999). O que pode denotar a pouca possibilidade de serem encontradas na água dos viveiros, levando em conta a presença de dejetos intestinais, como observado no presente trabalho.

\section{CONCLUSÃO}

Não foi detectada a presença de bactérias ácido-lácticas na água de viveiros da unidade experimental A, Na unidade B, a concentração destas bactérias foi ínfima, razão pelo qual não foi possível obter colônias isoladas das mesma e não ter apresentado efeito inibitório da cultura desenvolvida. Podendo assim inferir, que águas de viveiro não oferecem condições nutricionais e ambientais necessárias para estas bactérias se manterem em concentrações elevadas.

\section{REFERÊNCIAS}

AXELSSON, L. 1993. Lactic acid bacteria: classification and physiology. In: SALMINEN, S. VON WRIGHT, A. Lactic acid bacteria. New York: Marcel Dekker, p.1 $-63$.

ARGYRI, A. A. et al. Selection of potential probiotic lactic acid bacteria from fermented olives by in vitro tests. Food Microbiology, v.33, p. 282-291, 2013.

BAUER A.W; KIRBY W.M.M; SHERRYS J.C; TURK M. Antibiotic Susceptibility testing by a Standardized single disc method; Amer. J Clin Pathol 1966; 45: 493-496.

BORGUETTI, N.R.B; OSTRENSKY, A, BORGHETTI J.R. Aquicultura - Umavisão geral sobre a produção de organismos aquáticos no Brasil e no mundo. Curitiba: Grupo integrado de Aquicultura e Estudos Ambientais, 128p, 2003.

COSTA, A.B. Caracterização de bactérias do complexo Aeromonas isoladas de peixes de água doce e sua atividade patogênica. Piracicaba: Universidade de São Paulo, 2003. 54p. Tese (Doutorado em Ciência Animal e Pastagens) - Universidade de São Paulo, 2003.

COPPOLA, M.M., CONCEIÇÃO, F.R., GIL-TURNES, C. Effect of Saccharomyces boulardii and Bacillus cereus var. toyoi on the humoral and cellular response of mice to vaccines. Food and Agricultural Immunology, Basingstoke, v.16, (no prelo) 2004.

EFSA BIOHAZ PANEL (EFSA PANEL ON BIOLOGICAL HAZARDS), 2015. Statement on the update of the list of QPS-recommended biological agents intentionally 
added to food or feed as notified to EFSA 3: Suitability of taxonomic units notified to EFSA until September 2015. EFSA Journal 2015;13(12):4331, 25 pp. 2015.

FARZANFAR, A; The use of probiotics in shrimp aquaculture, Federation of European Microbiological Societies, v.48,p.149-158, 2006.

GATESOUPE,F.J. The use of probiotics in aquaculture. Aquaculture. 1999;180(12):147-165.

GILDBERG, A.; JOHANSEN, A.; BAGWALD, J. 1995 Growth and survival of Atlantic salmon (Salmo salar) fry given diets supplemented with fish protein hydrolysate and lactic acid bacteria during a challenge trial with Aeromonas salmonicida. Aquaculture, Amsterdam, 138: 23-34.

GOMEZ-GIL, B.; ROQUE, A.; TURNBULL, J.F. The use and selection of probiotic bacteria for use in the culture of larval aquatic organisms. Aquaculture, v. 191, p. 259270, 2000.

HUYS, L.; DHERT, P.; ROBLES, R.; OLLEVIER, F.; SORGELOOS, P.; SWINGS, J. 2001 Search for beneficial strains for turbot (Scophthalmus maximus L.) larviculture. Aquaculture, Amsterdam, 193: 25-37.

IBAMA, Estatísticas da pesca 2005 -Brasil, Grandes regiões e unidades da Federação. Brasília, 147p.2007.

OLAFSEN, J.A. 2001 Interactions between fish larvae and bacteria in marine aquaculture. Aquaculture, Amsterdam, 200: 223-247.

OSTRENSKY, Antonio Piscicultura : fundamentos e técnicas de manejo / Antonio Ostrensky, Walter Boeger.- Guaíba :Agropecuária, 1998.

RINGO, E., GATESOUPE, F.J. 1998. Lactic acid bactéria is fish: a review. Aquaculture.160:177.203.

SILVA, F.C.P.; BRITO, M.F.G.; FARIAS, L.M. et al. Composition and antagonistic activity of the indigenous intestinal microbiota of Prochilodus argenteus Agassiz. J. Fish Biol., v.67, p.1686-1698, 2005.

SILVA, A. P.R. Modelagem do crescimento de bactérias ácido lácticas em cultura pura e mista sob condições isotérmicas e não isotérmicas de cultivo. p. 194, 2015.

SINGH, K. et al. Probiotics: A review. Asian Pacific Journal of Tropical Biomedicine, p. 287-290, 2011.

VERSCHUERE, L.; ROUMBAUT, G.; SORGELOOS, P. and VERSTRAETE, W. Probiotic Bacteria as Biological Control Agents in Aquaculture. Microbiology and Molecular Biology Reviews, v. 64, n. 4, p. 655-671, 2000.

VAZQUEZ, J.A.; GONZÁLEZ, M.P.; MURADO, M.A. 2005 Effects of lactic acid bacteria cultures on pathogenic microbiota from fish. Aquaculture, Amsterdam, 245: $149-161$.

VINE, N.G.; LEUKES, W.D.; KAISER, H.; DAYA, S.; BAXTER, J.; HECHT, T. 2004 Competition for attachment of aquaculture candidate probiotic and pathogenic bactéria on fish intestinal mucus. Journal of Fish Diseases, Stirling, 27: 319-326.

WINTON J.R. Fish health management In: Fish Hatchery Management, 2nd edn, ed. By G. Wedemeyer), 559-639.American Fisheries Society, Bethesda, USA.2001. 